\title{
ENTERIC PATHOGENS OF DOGS AND CATS WITH PUBLIC HEALTH IMPLICATIONS
}

\author{
${ }^{1}$ Kantere, M., ${ }^{1}$ L.V. Athanasiou, ${ }^{1}$ D.C. Chatzopoulos, ${ }^{2}$ V. Spyrou, \\ ${ }^{1}$ G. Valiakos, ${ }^{3}$ V. Kontos and ${ }^{1} \mathrm{C}$. Billinis \\ ${ }^{1}$ Faculty of Veterinary Medicine, University of Thessaly, Karditsa, Greece \\ ${ }^{2}$ Department of Animal Production, Technological Educational Institute of Larissa, Greece \\ ${ }^{3}$ Department of Veterinary Public Health, National School of Public Health, Athens, Greece
}

Received 2014-02-09; Revised 2014-02-13; Accepted 2014-04-15

\begin{abstract}
Dogs and cats play an important role in modern society, enhancing the psychological and physiological well-being of many people. However, there are well-documented health risks associated with human animal interactions. More specifically, enteric pathogens of zoonotic risk which are transmitted by feces of dogs and cats can be grouped as follows: (a) Parasites such as Toxocara canis, T. cati, Ancylostoma $\mathrm{sp}$, Uncinaria sp, Strongyloides stercoralis, Echinococcus granulosus, E. multilocularis and Dipylidium caninum (b) Protozoa including Toxoplasma gondii, Giardia duodenalis and Cryptosporidium spp. (c) Bacteria of the genera Clostridium, Campylobacter, Salmonella, Escherichia, Yersinia and Helicobacter and (d) Viruses mainly Rotaviruses and Coronaviruses. Among them, Salmonella, Campylobacter, Rotaviruses, Toxoplasma gondii, Echinococcus have been reported to be of considerable importance for many countries including Greece. Even though official records of the cases in humans and livestock in Greece continuously decline, cystic echinococcosis is considered to be a serious problem for public health and livestock economy. Regarding other parasites, the overall prevalence of parasitism was $26 \%$ in owned shepherd and hunting dogs examined in Serres. Furthermore, seroepidemiological studies revealed the presence of antibodies against $T$. gondii in a considerable percentage of hospitalized children. Rotaviruses were confirmed as a major cause of acute gastroenteritis in children. Finally, bacterial zoonotic enteropathogens were identified in a notable number of pediatric cases. Most of these zoonoses are associated with the exposure of immunodeficient people or children to pets and/or conditions of poor hygiene. Studies on the presence of all these pathogens in animals are required to identify the extent of problem, to define control strategies and evaluate their effectiveness.
\end{abstract}

Keywords: Dog, Cat, Enteropathogens, Public Health, Zoonoses

\section{INTRODUCTION}

The relationship between humans and dogs began 12,000-15,000 years ago and with cats nearly 5,000 years ago (Morey, 1994). Nowadays, the number of dogs worldwide has been estimated to be more than 500 million. Apart from the psychological advantages, pet ownership has physiological benefits for many members of the society, such as a reduction in blood pressure
(Wilson, 1991), reduced medication (Headey and Krause, 1999) and increased one year survival after an acute myocardial infarction (Friedmann and Thomas, 1995).

Owning a dog or cat is a common phenomenon throughout the world: In the USA $61 \%$ of households have a pet and more than half of families that have a dog also have a child (Macpherson, 2005). Similarly in Europe percentages of companion animals including birds in households varies and the average is $52 \%$ for all Trikalon Str, 43100 Karditsa, Greece 
the 17 European countries (Macpherson, 2005). Unfortunately, the owners may abandon their pets which results in large numbers of unwanted stray dogs, mostly in countries without dog population well-established control programs, such as Greece (Macpherson, 2005).

Although human interaction with pets has been proven beneficial for pet owners, the risk of interspecies transmission of pathogens cannot be passed by when certain hygienic rules are not followed. Nowadays, control of zoonotic diseases is even more important due to the increasing number of immunocompromised people but the distribution of pets around the world and their differences modify their role in zoonotic disease transmission. The risk of pathogen transmission from pet to the owner is relatively small, when simple precautions are taken. Therefore, the role of veterinarians is essential since they have to provide pet owners with accurate information. This review focuses on zoonotic important enteropathogens, particularly these encountered in Greece and suggests preventive measures.

\section{ENTEROPATHOGENS OF COMPANION ANIMALS}

Numerous enteropathogens are detected in feces of dogs and cats but they do not all have the potential for transmission to humans (Bugg et al., 1999). Consequently, this review refers mostly to the enteropathogens with high risk of zoonotic transmission which can be classified as parasites, protozoa, bacteria and viruses, as summarized in Table 1.

\subsection{Intestinal Parasites}

The intestinal parasites with high risk of zoonotic transmission from animals to humans are divided in the following categories.

\subsubsection{Nematodes}

\subsubsection{Toxocara Canis/Toxocara Cati}

The prevalence of $T$. canis and $T$. cati has decreased during the last twenty years (Overgaauw, 1997; Bugg et al., 1999), probably due to the regular administration of broad-spectrum anthelmintics in companion animals. However, in USA, the most common zoonotic parasitic infestation acquired from companion animals was human toxocariasis (Schantz, 1994). People become infected when they accidentally ingest eggs containing $\mathrm{L}_{2}$ larvae. It has been shown (Holland et al., 1995) that Toxocara was present in the intestine of $80 \%$ of dogs younger than 6 weeks, although the results of fecal examination were often negative.
Table 1. Zoonoticenteropathogens; the most important zoonotic agents for Greece are marked

\begin{tabular}{ll}
\hline Parasites & \\
\hline I. Nematodes & II. Cestodes \\
Toxocaracanis (Greece) & Echinococcusgranulosus (Greece) \\
Toxocaracati & Echinococcusmultilocularis \\
Ancylostoma & Dipylidiumcaninum \\
Uncinaria & \\
Strongyloidesstercoralis & \\
Protozoa & \\
Toxoplasma gondii(Greece) & \\
Giardia duodenalis & \\
Cryptosporidium spp. & \\
Viruses & \\
Rotavirus (Greece) & \\
Coronavirus & \\
Bacteria & \\
Clostridium spp & \\
Salmonella spp. (Greece) & \\
Campylobacter spp. (Greece) & \\
E. coli & \\
Yersinia spp. &
\end{tabular}

The host becomes infected with $T$. cati by swallowing embryonated eggs of the parasite. It should be assumed that all young animals are infected with Toxocara and should be treated accordingly. In the external environment, the eggs survive for months and consequently toxocariasis represent a significant public health risk (Overgaauw, 1997).

\subsubsection{Ancylostoma/Uncinaria}

The larvae of hookworms (Ancylostoma and Uncinaria) can penetrate the skin of humans as well as the skin of canine or feline host. This disease is more common in areas of higher humidity (tropical and subtropical regions). Particularly, sunbathers or people who walk around barefooted are at higher risk of acquiring this infestation. It is probable that this condition is underdiagnosed, as the worm could be overlooked in pathological specimens and may be more common (Walker et al., 1995). If there are many larvae, they can penetrate into deeper tissue and cause pulmonary or intestinal symptoms (Robertson et al., 2002).

\subsubsection{Strongyloides Stercoralis}

Infection of dogs and cats with S. stercoralis is generally rare (Bugg et al., 1999). Infected animals may be asymptomatic; however, severe clinical illness can also occur. Severe diarrhea and bronchopneumonia can be caused by $S$. stercoralis. When massive infection occurs, the migration of the worm through the body may result in fever, nausea, vomiting and severe diarrhea. The disease can easily be confused with viral diseases, more common in young companion animals. In 
immunocompromised people, it can cause a lifethreatening disease (Siddiqui and Berk, 2001).

\subsection{Cestodes}

\subsubsection{Echinococcus granulosus/ E. multilocularis}

The life cycle of Echinococcus involves two mammalian hosts. The definitive hosts are carnivores (dogs in the case of E. granulosus, foxes and dogs for $E$. multilocularis) while the intermediate hosts (usually herbivores or humans) become infected by the accidental ingestion of eggs (Deplazes and Eckert, 2001). Playing with dogs without adult supervision could become risky for children, as eggs adhere to dog's hairs and children may accidently shallow them. After ingestion of the eggs the larvae develop into cysts (hydatid cysts-hydatid disease). Alveolar hydatid disease which is caused by $E$. multilocularis is an emerging infection in the USA, Western Europe and Japan and the cysts of $E$. multilocularis can invade internal organs leading to potentially life-threatening consequences (Deplazes and Eckert, 2001). Naturally, transmission of Echinococcus spp. results from a predator-prey relationship. However, human activities (i.e., feeding the viscera of homebutchered sheep to dogs or rabies vaccination through baiting of fox population in Europe) have resulted in establishment of wild animal cycles that serve as reservoirs (Thompson, 1992). The carcasses of animals close to urban areas are also potential sources of infection for companion animals.

\subsubsection{Dipylidium Caninum}

D. caninum is another intestinal tapeworm which can affect both dogs and cats. It is rarely found in humans. Fleas and lice are its intermediate hosts and final host becomes infected by ingesting cysticercoids (Raschka et al., 1994). Humans, especially children, become infected through accidental ingestion of infected fleas. This infection is usually asymptomatic. The symptoms from this infection are self-limiting and they disappear with time (Robertson et al., 2002).

\subsection{Protozoa}

\subsubsection{Toxoplasma Gondii}

Humans and other animals are frequently infected with T. gondii (Cook et al., 2000). Cats are the only definitive host for this parasite and they excrete oocysts (Tenter et al., 2000). In a study in the USA, less than $1 \%$ of cats examined have been shown to be shedding oocysts (Dubey, 1994). Humans become infected with $T$. gondii by ingesting soil contaminated by cat feces or more frequently by eating meat not properly cooked which contains bradyzoites or tachyzoites (Angulo et al., 1994; Cook et al., 2000). Infection with T. gondii is relatively common in humans and in most cases it is asymptomatic. The symptoms can vary from person to person when illness occurs. However, when an immunocompromised person or an unborn child becomes infected in utero, the clinical condition is far more dangerous. Also, humans can be infected with toxoplasmosis by organ transplant, but this is very rare (Robertson et al., 2002).

\subsubsection{Giardia Duodenalis}

G. duodenalis is considered to be the most common pathogenic intestinal parasite of humans and its prevalence has been found to be $2-7 \%$. Humans are likely to be the main reservoir of human giardiasis according to epidemiological evidence and person-toperson transmission is probably more important than zoonotic transmission (Schantz, 1991). However, dogs and cats can carry strains of Giardia which may be able to infect humans as well (Hopkins et al., 1997).In a recent study, the prevalence of Giardia spp. in stray dogs was found to be $7.14 \%$ (Mirzaei, 2010). Consequently, zoonotic transmission cannot be excluded, especially for immuno compromised people. Clinical giardiasis usually concerns kennels or catteries, which are overcrowded. These places are important sources of new pets for households, but these animals may be infected (Robertson et al., 2002). It is crucial to treat properly Giardia-infected dogs, even if they are not clinically ill, because of the potential for zoonotic transmission (Robertson et al., 2002).

\subsubsection{Cryptosporidium}

Cryptosporidium is a genus of protozoan pathogens and induces diarrhea in humans and domestic animals. Infection with Cryptosporidium is one of the most common non-viral causes of diarrhea (Current and Garcia, 1991). Most often Cryptosporidium affects children, particularly those who attend childcare centers. People may become infected with Cryptosporidium from their pets (Sargent et al., 1998). Among the eight different genotypes of C. parvum that have been reported only two appear to be capable of infecting immunocompetent humans (Morgan et al., 1997). However, it is possible for other genotypes, including the genotype found in dogs, to infect individuals, whose immune system does not function properly, as in HIV infected individuals (Pieniazek et al., 1999). Most infections of dogs with Cryptosporidium are asymptomatic. Clinical cryptosporidiosis appears to be 
most severe in children. Risk factors of acquiring cryptosporidiosis are stress, overcrowding and immune suppression (Robertson et al., 2002). In immunocompromised people infection can lead to a serious, life-threatening illness. Thus, early diagnosis and treatment is crucial.

\subsection{Bacteria}

\subsubsection{Campylobacter Spp}

Campylobacter spp. are gram-negative motile rods. There are 37 species and subspecies in the genus, but most of them are considered to be nonpathogenic. Many pathogenic campylobacter species such as C. jejuni ssp. jejuni and Campylobacter coli induce diarrhea in dogs, cats and humans (Marks et al., 2011). The association between diarrhea and the presence of Campylobacter in the feces has been investigated in many studies. However, it has been found that the isolation rates were similar in healthy and diarrheic animals (Sandberg et al., 2002; Rossi et al., 2008). In puppies and dogs younger than 12 months of age, it was observed that $C$. jejuni and C. upsaliensis had a prevalence rate in diarrheic animals over two times that of non diarrheic animals. This association was not observed in animals of older age (Burnens et al., 1992). When puppies were experimentally infected with $C$. jejuni, mild clinical disease occurred; therefore Campylobacter was considered potentially pathogenic (Makartney et al., 1988). It may be transmitted from dogs to humans, as a relationship between $C$. jejuni enteric diseases in humans with the ownership of a puppy has been found in epidemiologic analyses (Stafford et al., 2007). Children and immunocompromised individuals who own young pets are at greater risk of becoming infected by contact with dogs or cats while other sources of infection such as food products are the most commonly incriminated (Marks et al., 2011).

\subsubsection{Salmonella Spp}

Salmonellae are microorganisms that can infect mammals, birds, reptiles. Salmonellae are pathogenic for dogs and cats, but not all Salmonella strains can induce disease depending also on the infectious dose. The prevalence of Salmonella spp. in healthy dogs and cats was found to be equal as in animals with diarrhea in a study (Marks and Kather, 2003). In animals with diarrhea the prevalence of Salmonella spp. ranges from 0 to $3.5 \%$ in dogs (Van Duijkeren and Houwers, 2002; Hackett and Lappin, 2003) and from 0 to $8.6 \%$ in cats (Immerseel et al., 2004). The prevalence of Salmonella spp. in stray or shelter dogs and cats is $0-51.4 \%$ (Spain et al., 2001; Kocabiyik et al., 2006). Furthermore, the prevalence of Salmonella spp. was found to be much higher in dogs that are fed raw food diets and it was also isolated from $30 \%$ of the stool samples in greyhounds fed raw chicken diets (Joffe and Sclesinger, 2002). Salmonellosis is a disease of major zoonotic importance. All Salmonella microorganisms infect both animals and humans except for those causing human typhoid fever. More frequently, people become infected due to foodborne outbreaks after consuming contaminated products of animal origin that have been improperly stored or handled. It has been also observed (Gradel et al., 2008) that patients with malignancy in the hematopoietic system are at increased risk of being infected with Salmonella.

\subsubsection{Clostridium Spp}

Clostridium spp. are gram-positive anaerobic sporeforming bacilli. Clostridia are among the most widespread pathogenic bacteria and they are part of the natural micro flora of the gastrointestinal tract. $C$. perfringens and $C$. difficile are two of the most common enteropathogens which cause diarrhea in dogs. They are not considered pathogens of high zoonotic risk. However, they can be found in feces of the animals and spores survive in feces or decomposed tissues. People more often acquire this infection after consumption of contaminated food (Jhung et al., 2008; Songer, 2010) or during hospitalization. It was found that $C$. difficile was the cause of $10-21 \%$ of cases of diarrhea in dogs in the general population (Cave et al., 2002). In several studies $C$. difficile was found in $0-58 \%$ of healthy animals and especially in younger animals that visit human hospitals (Marks et al., 2002; Clooten et al., 2003). Consequently, it is safer for public health to consider $C$. difficile as potentially zoonotic (Arroyo et al., 2005; Weese et al., 2010). C. perfringens can be isolated from more than $80 \%$ of diarrheic and non-diarrheic dogs (Weese et al., 2001), whereas it is found more rarely in healthy cats and the isolation rates range between 43 and $63 \%$ (Marks et al., 2011). C. Perfringens Enterotoxin (CPE) is found in 34\% of diarrheic dogs (Weese et al., 2001). Animals may be responsible for transmission of the pathogen among species.

\subsubsection{Escherichia Coli}

E. coli are gram-negative, non-spore-forming rods belonging to the family Enterobacteriaceae. E. coli are part of the normal intestinal microflora, but they can cause gastroenteritis when local or systemic immunity 
does not function properly. Enteropathogenic strains of E. coli (EPEC) have been found in human patients and dogs that live in the same household (Rodrigues et al., 2004). In a more recent study, feces from 70 cats with diarrhea and 230 without diarrhea were collected and 15 enteropathogenic strains were isolated from 14 of them, whereas none enterotoxigenic E. coli (ETEC) or enterohemorrhagic E. coli (EHEC) were not found (Morato et al., 2009). Those strains include serotypes known as human pathogens. So, we should consider the possibility of zoonotic transmission in cases of disease outbreaks (Marks et al., 2011).

\subsubsection{Yersinia Enterocolitica}

Y. enterocolitica is a species of gram-negative coccobacillus-shaped bacteria, belonging to the family Enterobacteriaceae. It infects many animal species and it is resistant to the external environment (Wang et al., 2010). It has been isolated from feces of healthy dogs and cats. Domestic animals excrete $Y$. enterocolitica in their feces for many weeks and may be a source of infection for humans. In a survey in China from 2004 to 2008, 326 strains of $Y$. enterocolitica were isolated from people with diarrhea and it was demonstrated that there is a close relationship between strains of domestic dogs and of humans' strains (Wang et al., 2010). Nevertheless, the direct zoonotic transmission of $Y$. enterocolitica has not been proven until now (Robins-Browne, 1997). However, people who have come into contact with infected animals suffered from enterocolitis, indicating possible zoonotic transmission (Wang et al., 2010).

Other pathogens have also been reported as being responsible for causing zoonotic diseases such as Helicobacter spp, Anaerobiospirillum spp.

\subsection{Viruses}

\subsubsection{Rotaviruses}

Rotaviruses are pathogens which induce acute watery diarrhea in various host species, including birds and mammals. Rotaviruses are classified into a genus within the family Reoviridae. Their genome consists of 11 segments of double-stranded (ds) RNA (Estes, 2001; Kapikian, 2001). They are resistant to conditions of external environment. Until now, seven serogroups (A to $\mathrm{G})$ of rotavirus have been defined. Mainly group A Rotaviruses (GARVs) induce diarrhea in humans, mammals as well as poultry. GARVs infect individuals mainly via fecal-oral route. Their resistance in the environment may be responsible for water- or food-born transmission and outbreaks. Non-GARVs are not considered to be of importance for public health. GARVs are not considered as major enteric pathogens for companion animals but rotavirus-like particles were found in stool samples from both symptomatic and asymptomatic pets (Marshall et al., 1987). Rotaviruses usually affect particular species for which they have been defined as the homologous strains. However, heterologous rotavirus may infect other species in natural and experimental conditions. It has been proven that human GARV strains exist in stool samples from newborn animals with diarrhea (Kapikian, 2001). Nowadays there are plenty evidence for interspecies transmission and for genetic reassortment between human and animal Rotaviruses (Martella et al., 2009). The results of a recent study demonstrate that canine-like Rotaviruses may be responsible for interspecies transmission and also to induce severe forms of gastroenteritis in children. As most Rotavirus infections in pets may not be detected, the chance of complete epidemiologic surveillance is reduced. In conclusion, improving epidemiological surveillance in both animals and humans is crucial for understanding virus evolution, examining the results of the vaccines on reducing Rotavirus impacts and planning novel vaccine strategies.

\subsubsection{Coronaviruses}

Coronaviruses belong to family Coronaviridae and they are large, single stranded positive-sense RNA viruses. They infect many animal species and they cause enteric and respiratory disease (Enjuanes et al., 2000). Canine Coronavirus (CCoV) is an important enteropathogen of dogs, as it has caused many outbreaks (Decaro and Buonavoglia, 2008). CCoV is widespread in canine population, mainly in kennels and shelters, which are overcrowded, according to serological and virological investigations (Naylor et al., 2001; Schulz et al., 2008). Infection with Canine Coronavirus is characterised by high morbidity and low mortality and it is transmitted via the fecal-oral route (Tennant et al., 1991). It rarely infects people. However, The Severe Acute Respiratory Syndrome (SARS) is common and this fact has enhanced the suspicion that Coronaviruses may be responsible for zoonotic transmission. Besides that, in China, there were found SARS virus like Coronaviruses in a masked palm civet and a raccoon dog, two wild carnivore species. Following sequence analysis, the human and civet viruses' origin presented $99 \%$ homology although placed in different clusters (Bhardwaj, 2013). Also, changes in virulence, tissue tropisms and interspecies transmission of CCoVs have been found and they occur due to genetic variations in structural and non-structural proteins of the virus (Guan et al., 2003; Vijgen et al., 2005). In conclusion, 
zoonotic transmission cannot be excluded, as long as Coronaviruses are not strictly host specific.

\section{PUBLIC HEALTH SIGNIFICANCE}

Among all the above presented pathogens likely to cause zoonotic diseases in humans and especially in children, the most important are considered the following:

\subsubsection{Salmonella Spp}

Despite the advances in hygiene and handling of food, salmonellosis continues to be an important public health problem (Sánchez-Vargas et al., 2011). Salmonellosis is very common in developing countries; it affects mostly kids under 5 years old, while Salmonella spp. has become resistant to many antibiotics (Graham, 2002). In a recent study of 79 cases in U.S.A., a correlation was found between diarrhea due to Salmonella spp. and handling dry dog or cat food. In $49 \%$ of these cases, salmonellosis affected children under the age of two (Behravesh et al., 2010).

\subsubsection{Campylobacter Spp}

In a recent study, it was found that Campylobacter spp. was the most frequent bacterial cause of diarrhea in human patients during hospitalization in Great Britain (Tam et al., 2012), while it is one of the four most frequent causes of infectious enteritis in German patients (Epple and Zeitz, 2011). Children of age 0-35 months are more likely to be infected by Campylobacter spp. if they live in a household with a dog (Tenkate and Stafford, 2001).

\subsubsection{Rotavirus}

Rotaviruses are considered the most common cause of infectious diarrhea in young kids worldwide, especially in those of age 6-12 months (Yang and Fang, 2011) and the ownership of a pet seems to be an important risk factor (Bellido-Blasco et al., 2007).

\subsubsection{Toxoplasma Gondii}

Ocular toxoplasmosis is very common worldwide and it affects people in developing countries (Petersen et al., 2012). In a study in Brazil, it was found that 89 mothers were infected with $T$. gondii and their children had symptoms of the eyes (nystagmus, strabismus and retinal choroiditis) (Soares et al., 2012).

\subsubsection{Echinococcus Granulosus/E. multilocularis}

Echinococcosis is an important parasitic zoonosis found frequently at rural regions (Macpherson et al., 2003). In Europe, hunting, pet ownership and farming are important risk factors (Macpherson, 2005). From 2003 to 2010, 5483 persons were examined and 235 of them were found positive for echinococcosis in Poland (Wnukowska et al., 2011).

\section{UPDATE ON THE SITUATION IN GREECE}

In Greece, cystic echinococcosis is also considered a very important disease. It was a serious problem for public health in the 1970 s and since then, there is increased epidemiological surveillance: Strict controls on meat and other food products and management of stray animals. The prevalence of parasite has been reduced in human and in animal population, as human hydatidosis has decreased from percentage 14.8 per 100,000 inhabitants during the years from 1967 to 1971 to 0.3 per 100,000 in 2008 (Sotiraki and Chaligiannis, 2010). A survey in northern Greece, found that the prevalence of Echinococcus was $100 \%$ in sheep, $56.6 \%$ in cattle, $15.4 \%$ in goats and $9.3 \%$ in pigs and during the years from 1988 to 1999 , it was found that the seroprevalence for specific IgG was $29 \%$ in human population (Sotiraki et al., 2003). It seems that the parasitosis is still endemic in Greece.

In a recent study, stool samples from 232 healthy owned dogs from Serres were examined and it was found that the overall prevalence of parasitism was $26 \%$, with T. canis present in $12.8 \%$ of the cases, Giardia spp. in $4.3 \%, T$. leonina in $0.7 \%, D$. caninum in $0.3 \%$ (Papazahariadou et al., 2007).

In another study in northern Greece, seroprevalence for $\operatorname{IgG}$ and $\operatorname{IgM}$ specific to T. gondii was 1.25 and $1.1 \%$ in 1984 respectively, 1.05 and $0.93 \%$ in $1994,0.85$ and $0.8 \%$ in 2004 , while the intrauterine infections were estimated at 90-200 cases (Diza et al., 2005). Another study demonstrated that $11.1 \%$ of the 486 sera of children examined were positive to $\mathrm{IgG}$ antibodies against T. gondii (Frydas et al., 2000). Furthermore, a research which took place simultaneously in 5 pediatric hospitals, showed that rotavirus was the main cause of gastroenteritis in 166 of 393 children with gastroenteritis, i.e., $42.3 \%$ of non-hospitalized and in $47.8 \%$ of hospitalized patients, while $78.6 \%$ of the cases occured during winter and spring months (Koukou et al., 2010), as it is presented in Table 3. Finally, a study in Crete, which lasted from 1993 to 2010 included 33.032 stool samples which were tested and demonstrated that the 2912 samples were positive to enteropathogenic bacteria, with S. enterica $(42.3 \%)$ and Campylobacter spp. (33.6\%) to be the most frequently detected (Maraki et al., 2011). 


\section{PREVENTIVE MEASURES}

Simple procedures and practices may prevent the transmission of pathogens from feces via the oral route (fecal-oral route):

- Regular deworming of young and pregnant animals which may excrete a great number of parasites and other enteropathogens (Juckett, 1997)

- Washing hands carefully after playing with pets (Macpherson, 2005)

- Supervision of children during playing with companion animals or visiting public places

- Veterinarians should inform the owners about the risks of pet ownership and help them to avoid zoonotic transmission (Schantz and Glickman, 1983). Moreover, they should take the same precautions when handling animals since it is well known that they are also at great risk as well as breeders, groomers, veterinary nurses to become infected with zoonotic enteropathogens (Robertson and Thompson, 2002)

- Programs should be implemented to reduce stray animals' numbers: A major reservoir of enteropathogens (Macpherson, 2005)

Apart from contact with pets, other sources of infection should not be ruled out because of the presence of animals in a household. Improper preparation of food products and contamination of water or the environment are other common ways of acquiring a zoonotic infection (Smith et al., 2007).

Table 2. Population groups at higher risk of acquiring zoonotic infections caused by enteropathogens

Population groups susceptible to enteropathogens

Children

Elderly people

Pregnant women

Immunocompromised individuals

Persons professionally involved with animals

Table 3. Zoonotic diseases caused by enteropathogens of major importance in Greece

Zoonoses

Echinococcosis $29 \%$ seropositivity in human population of Greece

Toxocariasis

nothern greece $12.8 \%$ prevalence in healthy owned dogs in

Toxoplasmosis 90-200 cases of children's inautrerine infections

Rotaviruses Main cause of children's gastroenteritis in Greece

\section{CONCLUSION}

The most susceptible groups to enteropathogens are usually children (due to insufficient hygiene habits, geofagia) and the elderly, due to inadequate immune reactions. Also, pregnant women and immunocompromised individuals are at higher risk than other individuals. Finally, it is more common for people who are professionally involved with dogs or cats including veterinarians to become infected with zoonotic enteropathogens and this is summarized in Table 2. Changing habits is expected to contribute to the reduction of zoonotic transmission of enteropathogens (Macpherson, 2005). This is an important challenge for public health specialists, but results may be reached after long periods of time consuming efforts.

Presently, owners treat pets as family members and animals are free to wander in their households. Therefore, veterinarians should inform people about the risks and suggest preventive measures especially if they are parents or population at risk. Finally, surveillance is crucial to estimate the risk of infection and suggest casespecific preventive measures.

\section{ACKNOWLEDGEMENT}

This review has been partially co-financed by the European Union (European Social Fund-ESF) and Greek national funds through the Operational Program "Education and Lifelong Learning" of the National Strategic Reference Framework (NSRF) -Research Funding Program: Thales. Investing in knowledge society through the European Social Fund.

\subsection{Conflict of Interest}

None of the authors of this article has a financial or personal relationship with other people or organizations that could inappropriately influence or bias the content of this study.

\section{REFERENCES}

Angulo, F.J., C.A. Glaser, D.D. Juranek, M.R. Lappin and R.L. Regnery, 1994. Caring for pets of immunocompromised persons. J. Am. Vet. Med. Assoc., 205: 1711-1718. PMID: 7605476

Arroyo, L.G., S.A. Kruth, B.M. Wiley, H.R. Staempfli and D.E. Low et al., 2005. PCR ribotyping of Clostridium difficile isolates originating of human and animal sources. J. Med. Microbiol., 54: 163166. DOI: $10.1099 / \mathrm{jmm} .0 .47669-0$ 
Behravesh, C.B., A. Ferraro, M. Deasy, V. Dato and M. Moll et al., 2010. Human Salmonella infections linked to contaminated dry dog and cat food, 20062008. Pediatrics, 126: 477-483. DOI: 10.1542/peds.2009-3273

Bellido-Blasco, J.B., J.M. González-Cano, J.V. GalianoArlandis, C. Herrero-Carot and M.D. TiradoBalaguer et al., 2007. Risk factors for the occurrence of sporadic Campylobacter, Salmonella and rotavirus diarrhea in preschool children. An Pediatr 66: 367-74. PMID: 17430713

Bhardwaj, K., 2013. How prepared are we to control severe acute respiratory syndrome in future. Am. J. Virol., 2: 8-19. DOI: 10.3844/ajvsp.2013.8.19

Bugg, R.J., I.D. Robertson, A.D. Elliot and R.C.A. Thompson, 1999. Gastrointestinal parasites of urban dogs in Perth, Western Australia. Vet. J., 157: 295301. DOI: $10.1053 /$ tvjl.1998.0327

Burnens, A.P., B. Angéloz-Wick and J. Nicolet, 1992. Comparison of Campylobacter carriage rates in diarrheic and healthy pet animals. Zentralbl Veterinarmed B., 39: 175-180. PMID: 1642073

Cave, N.J., S.L. Marks, P.H. Kass, A.C. Melli and M.A. Brophy, 2002. Evaluation of a routine diagnostic fecal panel for dogs with diarrhea. J. Am. Vet. Med. Assoc., 221: 52-59. DOI: 10.2460/javma.2002.221.52.

Clooten, J.K., S.A. Kruth and J.S. Weese, 2003. Genotypic and phenotypic characterization of Clostridium perfringens and Clostridium difficile in diarrheic and healthy dogs. J. Vet. Int. Med., 17: 123. PMID: 12420824.

Cook, A.J., R.E. Gilbert, W. Buffolano, J. Zufferey and E. Petersen et al., 2000. Sources of Toxoplasma infection in pregnant women: European multicentre case-control study. Eur. Res. Netw. Congenital Toxoplasmosis, BMJ, 321: 142-147. PMID: 10894691

Current, W.L. and L.S. Garcia, 1991. Cryptosporidiosis. Clin. Lab. Med., 11: 873-897. PMID: 1802526.

Decaro, N. and C. Buonavoglia, 2008. An update on canine Coronaviruses: Viral evolution and pathobiology. Vet. Microbiol., 132: 221-234. DOI: 10.1016/j.vetmic.2008.06.007

Deplazes, P. and J. Eckert, 2001. Veterinary aspects of alveolar echinococcosis-a zoonosis of public health significance. Vet. Parasitol., 98: 65-87. DOI: 10.1128/CMR.17.1.107-135.2004

Diza, E., F. Frantzidou, E. Souliou, M. Arvanitidou and G. Gioula et al., 2005. Seroprevalence of Toxoplasma gondii in northern Greece during the last 20 years. Clin. Microbiol. Infect., 11: 719-723. DOI: 10.1111/j.1469-0691.2005.01193.x
Dubey, J.P., 1994. Toxoplasmosis. J. Am. Vet. Med. Assoc., 205: 1593-1598. PMID: 7730132

Enjuanes, L., D. Brian, D. Cavanagh, K. Holmes and M.M.C. Lai et al., 2000. Coronaviridae. In: Virus Taxonomy. Classification and Nomenclature of Viruses, Van Regenmortel, M.H.V., C.M. Fauquet, D.H.L. Bishop, E.B. Carsten and M.K. Estes et al. (Eds.), Academic Press, New York, ISBN-10: 0-12370200-3, pp: 835-849.

Epple, H.J. and M. Zeitz, 2011. Infectious enteritis. Internist, 52: 1038. DOI: 10.1007/s00108-011-2976-3

Estes, M., 2001. Rotaviruses and their Replication. In: Fields Virology, Estes, M. (Ed.), Lippincott Williams and Wilkins, Philadelphia, ISBN-13: 9780781718325, pp: 1747-1786.

Friedmann, E. and S.A. Thomas, 1995. Pet ownership, social support and one year survival after acutemyocardial infarction in the Cardiac Arrhythmia Suppression Trial (CAST). Am. J. Cardiol., 76: 12131217. DOI: 10.1016/S0002-9149(99)80343-9

Frydas, S., Y. Theodoridis, T. Rallis, K.K. AdamamaMoraitou and M. Papazahariadou et al., 2000. A seroepidemiological study of Toxoplasma gondii infection in children of northern Greece. Int. J. Immunopathol. Pharmacol., 13: 157-162. PMID: 12657205

Gradel, K.O., M. Nørgaard, C. Dethlefsen, H.C. Schønheyder and B. Kristensen et al., 2008. Increased risk of zoonotic Salmonella and Campylobacter gastroenteritis in patients with haematological malignancies: A population-based study. Ann. Hematol., 88: 761-767. DOI: 10.1007/s00277-008-0662-x

Graham, S.M., 2002. Salmonellosis in children in developing and developed countries and populations. Curr. Opin. Infect. Dis., 15: 507-512. PMID: 12686884

Guan, Y., B.J. Zheng, Y.Q. He, X.L. Liu and Z.X. Zhuang et al., 2003. Isolation and characterization of viruses related to the SARS Coronavirus from animals in southern China. Sci., 302: 276-278. DOI: 10.1126/science. 10870139

Hackett, T. and M.R. Lappin, 2003. Prevalence of enteric pathogens in dogs of north-central Colorado. J. Am. Anim. Hosp. Assoc., 39: 52-56. PMID: 12549614

Headey, B.W. and P. Krause, 1999. Health benefits and potential budget savings due to pets, Australian and German survey results. Aus. Social. Mon., 2: 4-6. DOI: 10.1023/A:1006892908532

Holland, C.V., P.O. Lorcain, M.R. Taylor and A. Kelly, 1995. Sero-epidemiology of Toxocariasis in school children. Parasitology, 5: 535-545. PMID: 7596638 
Hopkins, R.M., B.P. Meloni, D.M. Groth, J.D. Wetherall and J.A. Reynoldson et al., 1997. Ribosomal RNA sequencing reveals differences between the genotypes of Giardia isolates recovered from humans and dogs living in the same locality. J. Parasitol., 83: 444-451. PMID: 9057695

Immerseel, V.F., F. Pasmans, J. De Buck, I. Rychlik and H. Hradecka et al., 2004. Cats as a risk for transmission of antimicrobial drug-resistant Salmonella. Emerg. Infect. Dis., 10: 2169-2174. DOI: 10.320/eid1012.040904

Jhung, M.A., A.D. Thompson, G.E. Killgore, W.E. Zukowski and G. Songer et al., 2008. Toxinotype V Clostridium difficile in humans and food animals. Emerg. Infect. Dis., 14: 1039-1045. DOI: 10.3201/eid1407.071461

Joffe, D.J. and D.P. Schlesinger, 2002. Preliminary assessment of the risk of Salmonella infection in dogs fed raw chicken diets. Can. Vet. J., 43: 441442. PMID: 12058569

Juckett, G., 1997. Pets and Parasites. Am. Fam. Physician., 56: 1763-1774. PMID: 9371008

Kapikian, A.Z., 2001. A Rotavirus vaccine for prevention of severe diarrhea of infants and young children: Development, utilization and withdrawal. Novartis Found. Symp., 238: 153-171. PMID: 11444025

Kocabiyik, A.L., C. Cetin and D. Dedicova, 2006. Detection of Salmonella spp. in stray dogs in Bursa Province, Turkey: First isolation of Salmonella Corvallis from dogs. J. Vet. Med. B. Infect. Dis. Vet. Public Health, 53: 194-196. DOI: 10.1111/j. 1439-0450.2006.00932.x

Koukou, D., I. Grivea, E. Roma, H. Tsioni and G. Trimis et al., 2011. Frequency, clinical characteristics and genotype distribution of Rotavirus gastroenteritis in Greece (2007-2008). J. Med. Virol., 83: 165-169. DOI: $10.1002 / j m v .21945$

Macpherson, C.N., B. Bartholomot and B. Frider, 2003. Application of ultrasound in diagnosis, treatment, epidemiology, public health and control of Echinococcus granulosus and E. multilocularis. Parasitology, 127: 21-35. PMID: 15027603

Macpherson, C.N.L., 2005. Human behaviour and the epidemiology of parasitic zoonoses. Int. J. Parasitol., 35: 1319-1331. DOI: 10.1016/j.ijpara.2005.06.004

Makartney, L., R.R. Al-Mashat, D.J. Taylor and I.A. McCandlish, 1988. Experimental infection of dogs with Campylobacter jejuni. Vet. Rec., 122: 245-249. PMID: 3369054
Maraki, S., F. Ladomenou F.G. Samonis and E. Galanakis, 2011. Long-term trends in the epidemiology and resistance of childhood bacterial enteropathogens in Crete. Eur. J. Clin. Microbiol. Infect. Dis., 31: 18891894. DOI: 10.1007/s10096-011-1517-2

Marks, S.L. and E.J. Kather, 2003. Bacterial-associated diarrhea in the dog: A critical appraisal. Vet. Clin. North. Am. Small Anim. Pract., 33: 1029-1060. PMID: 14552160

Marks, S.L., E.J. Kather, P.H. Kass and A.C. Melli, 2002. Genotypic and phenotypic characterization of Clostridium perfringens and Clostridium difficile in diarrheic and healthy dogs. J. Vet. Intern. Med., 16: 533-540. PMID: 12322702

Marks, S.L., S.C. Rankin, B.A. Byrne and J.S Weese, 2011. Enteropathogenic bacteria in dogs and cats: diagnosis, epidemiology, treatment and control. J. Vet. Intern. Med., 25: 1195-1208. DOI: 10.1111/j.1939-1676.2011.00821.x

Marshall, J.A., M.L. Kennett, S.M. Rodger, M.J. Studdert and W.L. Thompson et al., 1987. Virus and virus-like particles in the faeces of cats with and without diarrhea. Aust. Vet. J., 64: 100-105. DOI: 10.1111/j.1751-0813.1987.tb09638.x

Martella, V., K. Bányai, J. Matthijnssens, C. Buonavoglia and M. Ciarlet, 2009. Zoonotic aspects of Rotaviruses. Vet. Microbiol., 140: 246-55. DOI: 10.1016/j.vetmic.2009.08.028

Mirzaei, M., 2010. Prevalence of stray dogswith intestinal protozoan parasites. Am. J. Anim. Vet. Sci., 5: 86-90. DOI: 10.3844/ajavasp.2010.86.90

Morato, E.P., L. Leomil, L. Beutin, G. Krause and R.A. Moura et al., 2009. Domestic cats constitute a natural reservoir of human enteropathogenic Escherichia coli types. Zoonoses Public Health, 56: 229-237. DOI: 10.1111/j. 1863-2378.2008.01190.x

Morey, D.F., 1994. The early evolution of the domestic dog. Sci. Am., 82: 336-347.

Morgan, U.M., C.C. Constantine, D.A. Forbes and R.C. Thompson, 1997. Differentiation between human and animal isolates of Cryptosporidium parvum using rDNA sequencing and direct PCR analysis. J. Parasitol., 83: 825-830. DOI: 10.1128/IAI.70.10.5670-5675.2002

Naylor, M.J., R.P. Monckton, P.R. Lehrbach and E.M. Deane, 2001. Canine Coronavirus in Australian dogs. Aus. Vet. J., 79: 116-119. DOI: 10.1111/j.1751-0813.2001.tb10718.x

Overgaauw, P.A., 1997. Aspects of Toxocara epidemiology: Toxocarosis in dogs and cats. Crit. Rev. Microbiol., 23: 233-251. DOI: $10.3109 / 10408419709115138$ 
Papazahariadou, M., A. Founta, E. Papadopoulos, S. Chliounakis and K. Antoniadou-Sotiriadou et al., 2007. Gastrointestinal parasites of shepherd and hunting dogs in the Serres Prefecture, Northern Greece. Vet. Parasitol., 148: 170-173. PMID: 17573197

Petersen, E., A. Kijlstra and M. Stanford, 2012. Epidemiology of ocular toxoplasmosis. Ocul. Immunol. Inflamm., 20: 68-75. DOI: 10.3109/09273948.2012.661115

Pieniazek, N.J., F.J. Bornay-Llinares, S.B. Slemenda, A.J. Da Silva and I.N. Moura et al., 1999. New cryptosporidium genotypes in HIV-infected persons. Emerg. Infect. Dis., 5: 444-449. PMID: 10341184

Raschka, C., W. Haupt and R. Ribbeck, 1994. Studies on endoparasitization of stray cat. Mon. Vet., 49: 307-315.

Robertson, B., M.I. Sinclair, A.B. Forbes, M. Veitch and M. Kirk et al., 2002. Case-control studies of sporadic cryptosporidiosis in Melbourne and Adelaide, Australia. Epidemiol. Infect. 128: 419443. DOI: 10.1017/S0950268802006933

Robertson, I.D. and R.C. Thompson, 2002. Enteric parasitic zoonoses of domesticated $\mathrm{dog}$ and cats. Microbes Infect., 4: 867-873. DOI: 10.1016/S12864579(02)01607-6

Robins-Browne, R.M., 1997. Yersinia Enterocolitica. In: Food Microbiology, Fundamentals and Frontiers, Doyle M.P., L.R. Beuchat, T.J. Montville (Eds), ASM Press, Washington D.C., ISBN-10: 1555811175, pp: 192-215.

Rodrigues, J., C.M. Thomazini, C.A. Lopes and L.O. Dantas, 2004. Concurrent infection in a dog and colonization in a child with a human enteropathogenic Escherichia coli clone. J. Clin. Microbiol., 42: 1388-1389. DOI: 10.1128/JCM.42.3.1388-1389.2004

Rossi, M., M.L. Hänninen, J. Revez, M. Hannula and R.G. Zanoni, 2008. Occurrence and species level diagnostics of Campylobacter spp., enteric Helicobacter spp. and Anaerobiospirillum spp. in healthy and diarrheic dogs and cats. Vet. Microbiol., 129: 304-314. DOI: 10.1016/j.vetmic.2007.11.014

Sánchez-Vargas, F.M., M.A. Abu-El-Haija and O.G. Gómez-Duarte, 2011. Salmonella infections: An update on epidemiology, management and prevention. Travel. Med. Infect. Dis., 9: 263-277. DOI: 10.1016/j.tmaid.2011.11.001

Sandberg, M., B. Bergsjø, M. Hofshagen, E. Skjerve and H. Kruse, 2002. Risk factors for Campylobacter infection in Norwegian cats and dogs. Prev. Vet. Med., 55: 241-253. DOI: 10.1016/S01675877(02)00095-8
Sargent, K.D., U.M. Morgan, A. Elliot and R.C. Thompson, 1998. Morphological and genetic characterisation of Cryptosporidium oocysts from domestic cats. Vet. Parasitol., 77: 221-227. PMID: 9763312

Schantz, P.M, 1994. Of worms, dogs and human hosts: continuing challenges for veterinarians in prevention of human disease. J. Am. Vet. Med. Assoc., 204: 1023-1028. PMID: 8045801

Schantz, P.M. and L.T. Glickman, 1983. Ascarids of cats and dogs: A public health and veterinary medicine problem. Bol. Oficina. Sanit. Panam., 94: 571-586. PMID: 6224494

Schantz, P.M., 1991. Parasitic zoonoses in perspective. Int. J. Parasitol., 21: 161-170. DOI: 10.1016/00207519(91)90006-S

Schulz, B.S., C. Strauch, R.S. Mueller, W. Eichhorn and K. Hartmann, 2008. Comparison of the prevalence of enteric viruses in healthy dogs and those with acute haemorrhagic diarrhoea by electron microscopy. J. Small Anim. Pract., 49: 84-88. DOI: 10.1111/j.1748-5827.2007.00470.x

Siddiqui, A.A. and S.L. Berk, 2001. Diagnosis of Strongyloides stercoralis infection. Clin. Infect. Dis., 33: 1040-1047. DOI: 10.1086/322707

Smith, H.V., S.M. Caccio, N. Cook, R.A.B. Nichols and A. Tait, 2007. Cryptosporidium and Giardia as foodborne zoonoses. Vet. Parasitol., 149: 29-40. DOI: 10.1016/j.vetpar.2007.07.015

Soares, J.A., S.F. Carvalho and A.P. Caldeira, 2012. Profile of pregnant women and children treated at a reference center for congenital toxoplasmosis in the northern state of Minas Gerais, Brazil. Rev. Soc. Bras. Med. Trop., 45: 55-59. DOI: 10.1590./S003786822012000100011

Songer, J.G., 2010. Clostridia as agents of zoonotic disease. Vet. Microbiol., 140: 399-404. DOI: 10.1016/j.vetmic.2009.07.003

Sotiraki, S. and I. Chaligiannis, 2010. Cystic echinococcosis in Greece. Past and present. Parasite, 17: 205-210. DOI: 10.1051/parasite/2010173205

Sotiraki, S., C. Himonas and P. Korkoliakou, 2003. Hydatidosis-echinococcosis in Greece. Acta Trop., 85: 197-201. DOI: 10.1016/s0001-706x(02)00273-5

Spain, C.V., J.M. Scarlett, S.E. Wade and P. McDonough, 2001. Prevalence of enteric zoonotic agents in cats less than 1 year old in central New York State. J. Vet. Intern. Med., 15: 33-38. PMID: 11215908. 
Stafford, R.J., P. Schluter, M. Kirk, A. Wilson and L. Unicomb et al., 2007. A multi-centre prospective case-control study of Campylobacter infection in persons aged 5 years and older in Australia. Epidemiol. Infect., 135: 978-988. DOI: 10.1017/S0950268806007576

Tam, C.C., S.J. O'Brien, D.S. Tompkins, F.J. Bolton and L. Berry et al., 2012. Changes in causes of acute gastroenteritis in the United Kingdom over 15 years: Microbiologic findings from 2 prospective, population-based studies of infectious intestinal disease. Clin. Infect. Dis., 54: 1275-1286. DOI: $10.1093 / \mathrm{cid} / \mathrm{cis} 028$

Tenkate, T.D. and R.J. Stafford, 2001. Risk factors for Campylobacter infection in infants and young children: A matched case-control study. Epidemiol. Infect., 127: 399-404. DOI: 10.1017/S0950268801006306

Tennant, B.J., R.M. Gaskell, D.F. Kelly and S.D. Carter, 1991. Canine Coronavirus infection in the dog following oronasal inoculation. Res. Vet. Sci., 51: 11-18. DOI: 10.1016/0034-5288(91)90023-H

Tenter, A.M., A.R. Heckeroth and L.M. Weiss, 2000. Toxoplasma gondii: From animals to humans. Int. J. Parasitol., 30: 1217-1258. DOI: 10.1016/S00207519(00)00124-7

Thompson, R.C., 1992. Parasitic zoonoses-problems created by people, not animals. Int. J. Parasitol., 22: 556-561. PMID: 1399238

Van Duijkeren, E. and D. Houwers, 2002. Salmonella enteritis in dogs, not relevant? Tijdschr. Diergeneeskd, 127: 716-717. PMID: 12491970

Vijgen, L., P. Lemey, E. Keyaerts and M.V Ranst, 2005. Genetic variability of human respiratory Coronavirus OC43. J. Virol. Mar., 79: 3223-3224. DOI: $10.1016 /$ j.virol.2005.04.010
Walker, N.I., J. Croese, A.D. Clouston, M. Parry and A. Loukas et al., 1995. Eosinophilic enteritis in northeastern Australia. Pathology, association with Ancylostoma caninum and implications. Am. J. Surg. Pathol., 19: 328-337. PMID: 7872431

Wang, X., Z. Cui, H. Wang, L. Tang and J. Yang et al., 2010. Pathogenic Strains of Yersinia enterocolitica Isolated from Domestic Dogs (Canis familiaris) Belonging to Farmers Are of the Same Subtype as Pathogenic Y. enterocolitica Strains Isolated from Humans and May Be a Source of Human Infection in Jiangsu Province, China. J. Clin. Microbiol., 48: 1604-1610. DOI: 10.1128/JCM.01789-09

Weese, J.S., H.R. Staempfli, J.F. Prescott, S.A. Kruth and S.J. Greenwood et al., 2001. The roles of Clostridium difficile and enterotoxigenic Clostridium perfringens in diarrhea in dogs. J. Vet. Int. Med., 15: 374-378. PMID: 11467596

Weese, J.S., R. Finley, R.R. Reid-Smith, N. Janecko and J. Rousseau, 2010. Evaluation of Clostridium difficile in dogs and the household environment. Epidemiol. Infect, 138: 1100-1104. DOI: $10.1017 /$ S0950268809991312

Wilson, C.C., 1991. The pet as an anxiolytic intervention. J. Nerv. Ment. Dis., 179: 482-489. PMID: 1856711

Wnukowska, N., R. Salamatin and E. Gołab, 2011. Human echinococcosis in Poland in 2003-2010 according to the serological tests results of NIPHNIH. Przegl. Epidemiol., 65: 455-458. PMID: 22184948

Yang, L.M. and Y.C. Fang, 2011. Clinical investigate and epidemiological of Rotavirus enteritis in children. Zhonghua Shi Yan He Lin Chuang Bing Du Xue Za Zhi, 25: 371-373. PMID: 22338228 